\title{
Structural deformation and fluid flow from East Sichuan to the northwestern periphery of the Xuefeng Uplift, China
}

\author{
Tang Liangjie ${ }^{1,2 *}$ and Cui Min ${ }^{3}$ \\ ${ }^{1}$ State Key Laboratory of Petroleum Resources and Prospecting, China University of Petroleum, Beijing 102249, China \\ ${ }^{2}$ Basin Research Center, China University of Petroleum, Beijing 102249, China \\ ${ }^{3}$ CNOOC Research Institute, Beijing 100027, China
}

(C) China University of Petroleum (Beijing) and Springer-Verlag Berlin Heidelberg 2012

\begin{abstract}
Hydrocarbon preservation conditions have restricted exploration in the Middle and Upper Yangtze, and structural deformation and fluid activity have played an important role in the origin and preservation of oil and gas. In order to study that how the deformation and fluid activity impact the hydrocarbon preservation, we did some field work and collected some calcite vein samples for analysis of deformation periods using acoustic emission and fluid inclusions. Combined with previous studies, the strata distribution, tectonic deformation and fluid characteristics show that there are three structural belts in the study area: East Sichuan, West Hunan and Hubei and the northwestern periphery of the Xuefeng Uplift, and that their tectonic deformation style, fluid inclusion characteristics and hydrocarbon preservation are different. The breakthrough thrusts were well developed in the anticline core, and a lot of hydrocarbon inclusions were found in calcite veins around the thrusts in East Sichuan. The breakthrough thrusts were only in the syncline core in West Hunan and Hubei, and the brine inclusions did not contain hydrocarbon in calcite veins around the thrusts. Many breakthrough thrusts were found in the northwestern periphery of the Xuefeng Uplift, where there were only rare calcite veins. The deformation and hydrocarbon inclusion indicated that when there was no fault breakthrough in East Sichuan, the Paleozoic covered by the Triassic regional cap was good for hydrocarbon preservation. The strata above the Lower Paleozoic were denuded, and lots of brine inclusions and deep infiltration of surface water were found in the West Hunan and Hubei, so only the part of the syncline area with a well developed Silurian regional cap had good preservation conditions. Intense tectonic movements and denudation were widely developed in the northwestern periphery of the Xuefeng Uplift, where there were only paleo-reservoirs, non-hydrocarbon fluid activity and poor preservation conditions.
\end{abstract}

Key words: Structural deformation, fluid flow, preservation conditions, fluid inclusion, Middle and Upper Yangtze

\section{Introduction}

The Upper Yangtze is a part of the Yangtze platform, where many petroliferous basins have been discovered. During the Upper Sinian to Middle Triassic, the marine sedimentary rocks were well developed. After the Middle Triassic transitional facies deposits, only the lacustrine and fluvial facies are distributed in local area (Fig. 1). Until now the discovered oil and gas fields are mainly fractured carbonate reservoirs, which are multi-cycle, multi-layer system, multiple source rocks and accumulation. In recent years, large to medium-sized Upper Permian - Lower Triassic carbonate

*Corresponding author. email: tanglj@cup.edu.cn

Received August 21, 2011 gas reservoirs have been found, which demonstrates the excellent prospects of natural gas exploration in the area.

As there has been intense tectonic activity in the Middle and Upper Yangtze, the preservation condition has become a key factor influencing the hydrocarbon exploration in South China (Janssen et al, 1998). Tectonics, cap rock and fluids are considered to be the main static factors controlling the preservation condition, and tectonics and fluids are mutually restricted and promoted (Qiu, 1996; Tang et al, 2009). The presence of faults and a large number of fluid inclusions reflects the thermal events caused by tectonic activity (Antonellini and Aydin, 1995; Jones et al, 1998; Mei et al, 2008). Based on the analysis of fluid inclusions around the faults, we can not only reveal the migration characteristics of fluids (oil, gas, water), but also can provide evidence for tectonic activity and evolution (Sun et al, 2002; Shen et al, 
2003; Xu et al, 2007). To study the structural deformation and structural periods of the Upper Yangtze Block, we selected the structural belt from East Sichuan to the Xuefeng Uplift to collect samples and undertook a detailed structural observation. According to the structural periods reflected by the acoustic emission interpretation of structural deformation, we divided the Middle and Upper Yangtze Block into different belts, and measured the homogenization temperatures of fluid inclusions in the calcite veins and analyzed the fluid data such as groundwater composition. Therefore, we can determine the characteristics of fluid flow and the relation between fluid flow and structural deformation.

\section{Structural characteristics and deformation periods from East Sichuan to the northwestern periphery of the Xuefeng Uplift}

In order to study the structural deformation and periods, we took samples for later examination of acoustic emission in three structural belts of the study area, and tested 108 samples of 36 groups from 12 sites (Fig. 1) in the Sichuan Key Laboratory of Geotechnical Engineering, Institute of Water Conservancy and Hydropower, Sichuan University.

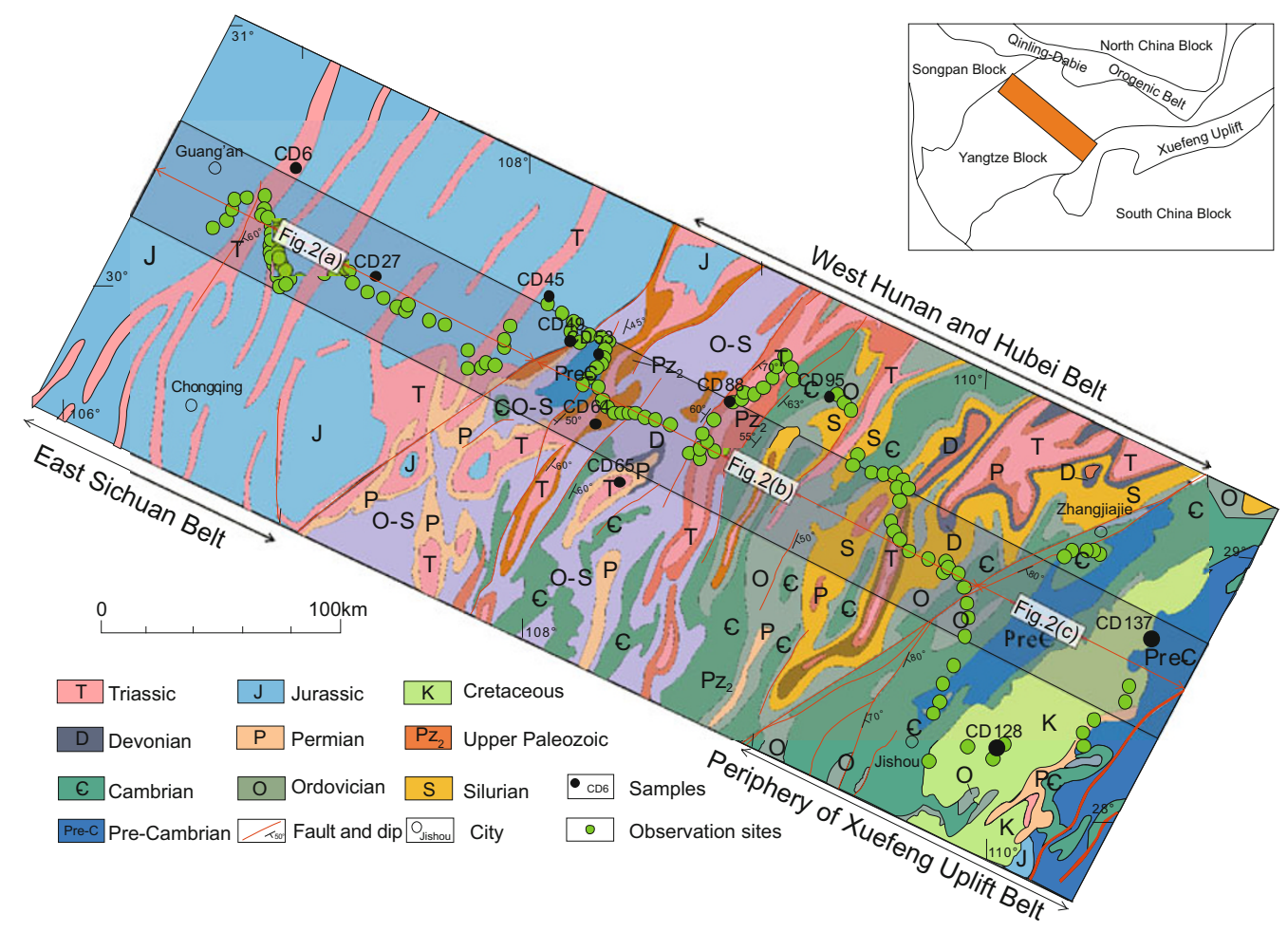

Fig. 1 Observations and acoustic emission samples on outcrop from East Sichuan to the periphery of the Xuefeng Uplift

\subsection{East Sichuan chevron anticline belt}

The East Sichuan chevron anticline belt developed many closed anticlines and gentle synclines (Fig. 2(a)). The structural deformation of East Sichuan was mainly controlled by the detachment of Lower Triassic rock salt and mudstone (Tang and Cui, 2011). The detachment was relatively shallow, and there were several high steep anticline belts, with the ratio of anticline width to syncline width about 1:3. The Triassic carbonates were distributed in the core of anticlines. The west limb of the anticlines was steep and upright to reverse, and the east limb was relatively gentle. The Jurassic clastics were distributed in the gentle syncline fold belt (Fig. 2(a)). Except for the Huayingshan fault in the west of anticlines which dipped to east, all the other faults did not outcrop, and these blind faults were all derived from the Huayingshan fault (Fig. 2(a)).

We collected acoustic emission samples at four sites and tested them. The sampling sites were CD-06, CD-27, CD45 and CD-49 (Table 1 and Fig. 2(a)). The Lower Cretaceous was the youngest strata in the fold deformation. Based on the acoustic emission results, there were four tectonic movements, the Indo-China, early Yanshan, late Yanshan and Himalayan movements. The first three were the key movements, and controlled the structural characteristics. The latest strata in the northeast and southwest of the East Sichuan chevron anticline belt were Jurassic and Lower Cretaceous, and the Quaternary was not constrained by the structural characteristics. So the main tectonic movements which control the structure now are from the Late Triassic to the Late Cretaceous. The Permian sample CD-49 and the Triassic sample CD-06 were located in the boundary of structural belts, and had experienced four to five tectonic movements, more than the Jurassic samples. Their movements were weak, because the conversion from land to sea in the Indo-China movement affected the paleostress. 


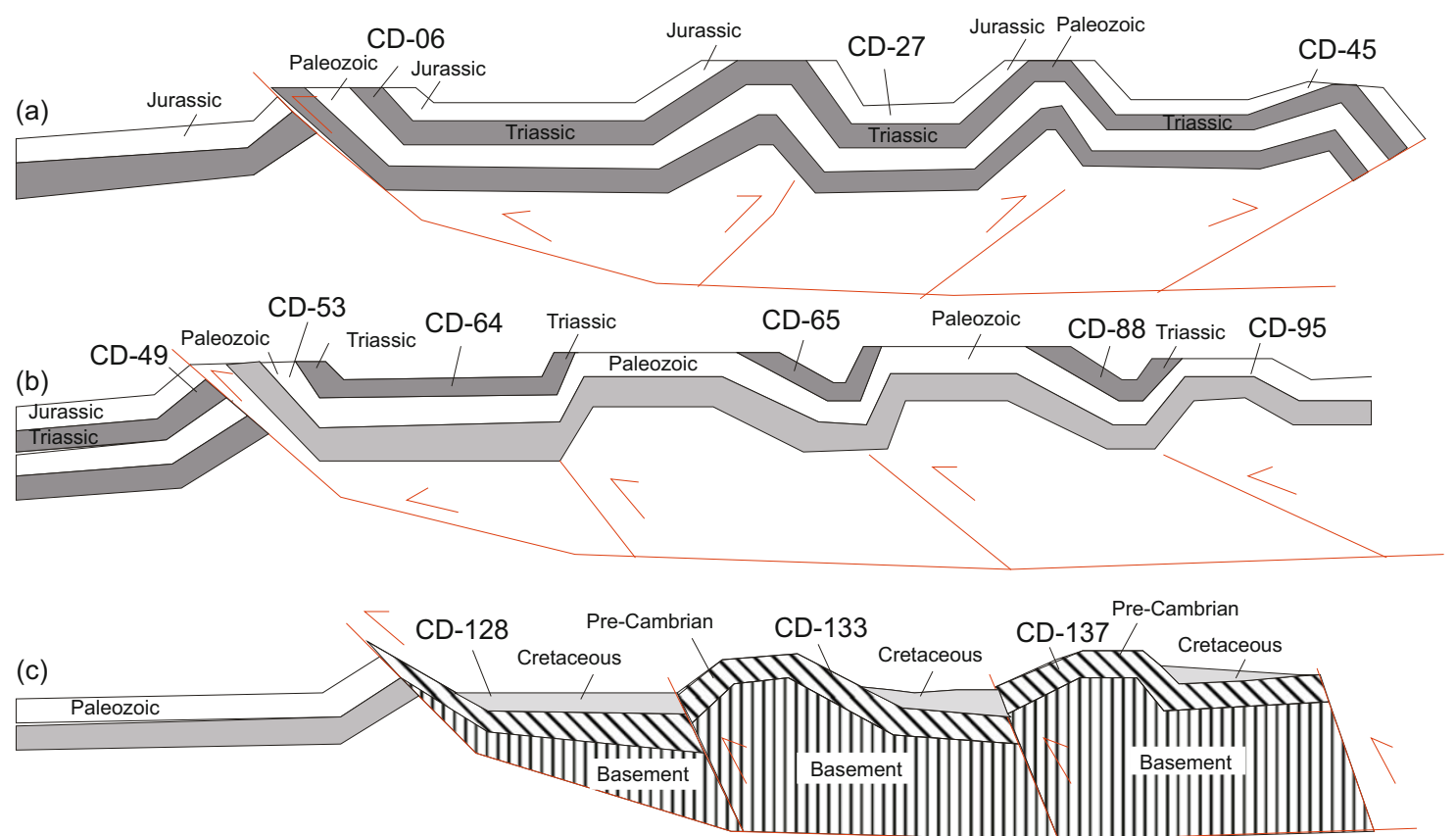

Fig. 2 Tectonic deformation styles of faults from East Sichuan to the Xuefeng Uplift (location see Fig. 1)

(a) East Sichuan; (b) West Hunan and Hubei; (c) The periphery of the Xuefeng Uplift

Table 1 Acoustic emission results from East Sichuan to the northwestern periphery of the Xuefeng Uplift

\begin{tabular}{|c|c|c|c|c|}
\hline Structural belt & Sample & Stratum & Principal stress, $\mathrm{MPa}$ & Tectonic events \\
\hline \multirow{4}{*}{ East Sichuan } & CD-06 & Triassic & $8.29,14.67,24.73,35.01$ & 4 \\
\hline & CD-27 & Jurassic & $8.35,14.56,34.40$ & 3 \\
\hline & CD-45 & Jurassic & $15.00,35.46,93.03$ & 3 \\
\hline & CD-49 & Permian & $15.01,27.20,32.40,71.85,86.54$ & 5 \\
\hline \multirow{5}{*}{ West Hunan and Hubei } & CD-53 & Cambrian & $26.46,30.71,34.46,46.59,54.70,67.58$ & 6 \\
\hline & CD-64 & Permian & $26.27,45.51,58.48,70.60$ & 4 \\
\hline & CD-65 & Triassic & $24.87,57.58,73.02$ & 3 \\
\hline & CD-88 & Triassic & $14.17,23.85,32.80,56.53,71.55$ & 5 \\
\hline & CD-95 & Ordovician & $13.22,25.50,35.54,48.23,59.26,71.30$ & 6 \\
\hline \multirow{3}{*}{ Periphery of the Xuefeng Uplift } & CD-128 & Cretaceous & $30.94,44.59$ & 2 \\
\hline & CD-133 & Banxi Group & $15.24,28.03,33.80,43.05,54.85,67.98,88.96$ & 7 \\
\hline & CD-137 & Sinian & $16.04,26.83,37.03,47.17,59.38,74.91,92.81$ & 7 \\
\hline
\end{tabular}

Samples CD-27 and CD45 were Jurassic. Although they were from different structural positions, the acoustic emission characteristics were similar, which showed that they suffered the same three tectonic deformations. The former was located in the syncline core of the central structural belt with low tectonic stress. The latter was located in the anticline core of the structural belt boundary with high tectonic stress. Comparing the deformation intensity from east to west in the East Sichuan structural belt, we can see that the deformation was transferred from east to west (Fig. 1 and Table 1).

\subsection{West Hunan and Hubei fault-fold belt}

The West Hunan and Hubei region is located in the northwestern periphery of the Middle and Upper Yangtze Block. Previous studies indicated that West Hunan and Hubei was a stable platform, formed in the Jinning movement, with a crystalline and folded basement (Mei et al, 2010; He et al, 2011). The same as the East Sichuan belt, the main structural direction was NE-NEE, and EW in local parts in West Hunan and Hubei, which reflected that they had the same tectonic background, and the evolution of the Xuefeng Uplift controlled the structural styles (Fan et al, 2006; Mei et al, 2010).

The faults were distributed in the west side of the anticline, and dipped east (Fig. 1). The occurrence of faults was moderate and there were many secondary east- 
dipping faults. The fold belt was composed of many complex anticlines and synclines, whose distribution was characterized as follows: from SE to NW the fold strength became weak, the uplifting amplitude became smaller and the strata became younger. The detachment was deeper than the East Sichuan, mainly Silurian and Lower Cambrian mudstone (Fig. 2(b)).

There were five sites for field work in the West Hunan and Hubei. We collected samples for acoustic emission samples and tested them. The sites were CD-53, CD-64, CD-65, CD-88 and CD-95 (Fig. 1 and Fig. 2(b)). The basic structure of West Hunan and Hubei was established during the Caledonian movement, and the later tectonic movements reformed them (Janssen et al, 1998; Mei et al, 2008; Tang and Cui, 2011). As shown by the acoustic emission characteristics in the East Sichuan belt, the deformation was weak in the central structural belt, while the deformation was strong on the boundary. In the contact region between East Sichuan and the West Hunan and Hubei, there was one more tectonic period shown in the Cambrian sample CD-53 than in the Permian sample CD-49, and the Ordovician sample CD-95 and the Cambrian sample CD-53 had a similar number of tectonic periods. For the Triassic samples, the structural stress in West Hunan and Hubei (CD-65 and CD-88) was stronger than that in the East Sichuan (CD-06). Combined with the regional tectonic evolution of Middle and Upper Yangtze, the basic structural characteristics of West Hunan and Hubei were established during the Caledonian movement. After structural transformation, in West Hunan and Hubei, the outcrop strata were older than those in the East Sichuan. In addition, the maximum structural stress in the West Hunan and Hubei was relatively homogeneous, about $70 \mathrm{MPa}$.

\subsection{Northwestern periphery of the Xuefeng Uplift thrust structural belt}

The main outcropping strata in the northwestern periphery of the Xuefeng Uplift were the Pre-Cambrian and the Upper Cretaceous. The Pre-Cambrian was mainly distributed in the core of anticline and the fault was located in the west of anticline, dipping east (Fig. 2(c)). The Upper Cretaceous clastic rocks were well developed in the footwall of the fault, showing that the study area experienced extension, forming local terrestrial lake sediments.

Samples for acoustic emission study were collected from the Banxi Group, Silurian and Upper Cretaceous. Because the study area was near the Xuefeng Uplift, the structural characteristics were influenced by the evolution of the Xuefeng Uplift. The youngest strata involved in the thrust structure in the northwestern of the Xuefeng Uplift were Jurassic, and the Upper Cretaceous uncomfortably overlay the thrust fault, so the thrust fault occurred before the Upper Cretaceous. The Jurassic outcropped only in the Guiyang area which was far from the Xuefeng Uplift, so we think the thrust fault may have experienced multiple periods of thrusting.

The Upper Cretaceous samples from the northwestern periphery of the Xuefeng Uplift showed that there were two tectonic movements (late Yanshan and Himalayan) after the Early Cretaceous. Combined with the distribution characteristics of Triassic and Jurassic samples, we can conclude that the early Yanshan movement controlled the overall structural characteristics. The distribution characteristics of Lower Cretaceous in the southwest showed that the NE and NW structures were superimposed and the structure of basement affected the current structures.

\section{Fluid flow from East Sichuan to the northwestern periphery of the Xuefeng Uplift}

Tectonic activities and fluid flow restricted oil and gas preservation in the Middle and Upper Yangtze Block, and the fluid inclusions and hydrogeological studies provided the most direct evidence for hydrocarbon migration (Lou et al, 2008). During the crystallization process from fluid, the surrounding gas, oil, and water were captured into the crystals, and these fluid inclusions retained the generation, migration and evolution information of oil and gas in the basin (Shen et al, 2003).

In order to study the preservation conditions of oil and gas in the Middle and Upper Yangtze Block, we collected the calcite veins samples and analyzed the homogenization temperature of fluid inclusions (Fig. 1). Eighteen calcite veins samples were collected, including nine in East Sichuan, seven in West Hunan and Hubei, two in the northwestern periphery of the Xuefeng Uplift. The fluid inclusions were all formed in calcite veins, and were primary inclusions, irregular in shape (Fig. 2).

The homogenization temperatures of the fluid inclusions were determined in the Geochemical Laboratory of China University of Petroleum (Beijing). The fluid inclusion analysis using transmitted light and fluorescence was performed with the MPV-SP microscope photometer, THM600 coldhot stage produced by Linkam, UK. The range of measured temperature was $-190-600^{\circ} \mathrm{C}$.

Nine samples were collected from calcite veins in East Sichuan, including eight Triassic and Permian carbonate rock samples, one Jurassic sandstone sample. The veins were well developed around the Huayingshan fault and derivative faults (Fig. 1). The peak homogenization temperatures of all vein fluid inclusions were between $70-110{ }^{\circ} \mathrm{C}$ (Fig. 3), of which six samples had oil and gas inclusions, and the rest were brine inclusions. The Paleozoic was covered by Mesozoic in East Sichuan, forming a good regional cap. The oil and gas-rich fluid inclusions were mainly located in the Permian and Triassic, so the oil and gas fluid had migrated into the Permian and Triassic. The Permian-Middle Triassic, distributed in the core of high and steep anticlines, exposed to the surface in East Sichuan, resulting in dilution of the formation water, decrease of the salinity, increase of the metamorphic coefficient and desulfurization coefficient, with $\mathrm{Na}_{2} \mathrm{SO}_{4}$ and $\mathrm{NaHCO}_{3}$ type water. It was shown that the hydrocarbon preservation condition was poor, such as in the Shiyougou-Shilongxia area (Liu et al, 2011). However, the water composition was favorable for hydrocarbon preservation in the wide and gentle syncline area such as well Xin5 (Xu et al, 1999; Wang et al, 2001; Cheng et al, 2005). The discovery of the Jiannan gas field has proved that there 


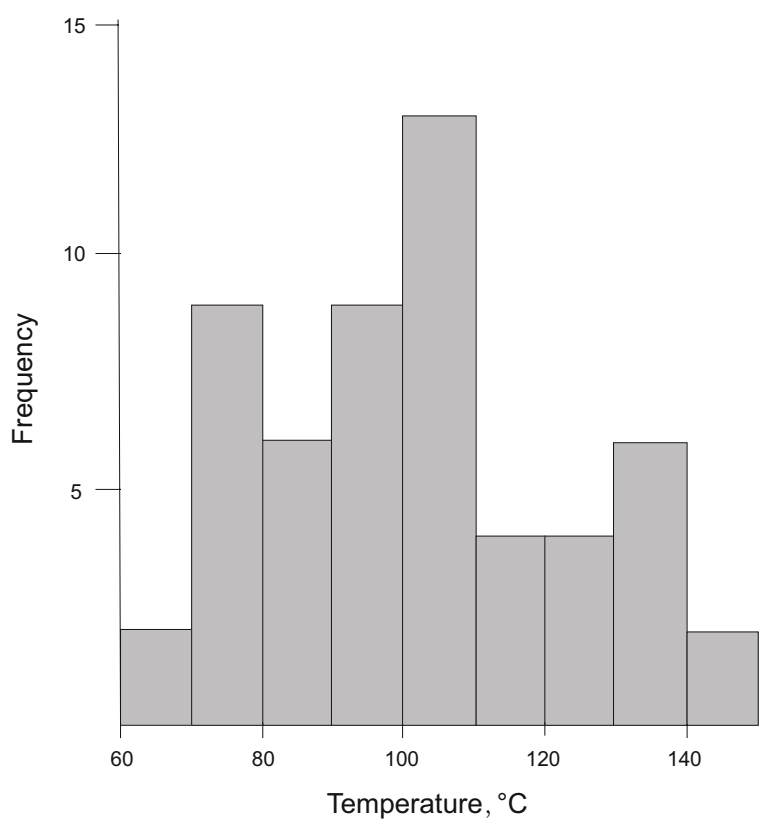

Fig. 3 The histogram of homogenization temperatures of fluid inclusions in East Sichuan

are some good oil and gas preservation conditions.

Seven samples were collected from the calcite veins in West Hunan and Hubei (Table 2). The samples were from the anticline cores in the west and the syncline cores in the east which was near the Xuefeng Uplift. It is shown that the fluid activity was intense in the east of West Hunan and Hubei, with surface contact and poor preservation conditions. The synclines in the west were good for oil and gas preservation. There was only the Permian sample showing gas inclusions among the seven samples. The peak of homogenization temperature of all vein fluid inclusions was between $75-90{ }^{\circ} \mathrm{C}$ (Fig. 4). The formation water was often found in the Lower Paleozoic, with low salinity and metamorphic coefficient generally greater than 2 , which reflected that the meteoric water had infiltrated strongly, and the water chemistry conditions were poor for hydrocarbon preservation in West Hunan and Hubei (Liu et al, 2011). Previous researchers analyzed the $\mathrm{C}$ and $\mathrm{O}$ isotopes of Cambrian core samples in well Li 1, which showed that there was a weak difference in $\mathrm{C}$ isotopic value and a large difference in $\mathrm{O}$ isotopic value between the vein and the wall rock. Taking the Sr isotope data into account, the Lower and Upper Cambrian fluids were directly from the Cambrian, and the fluid systems were separated from each other. The Lower Cambrian was relatively good for hydrocarbon preservation in the central anticlinorium belt. The Upper Paleozoic was denuded in West Hunan and Hubei, with poor preservation conditions. For the Lower Paleozoic, the Silurian and Cambrian regional cap rocks were good for oil and gas preservation, and oil and gas fluid flow was weak (Mei et al, 2010; He et al, 2011).

Table 2 Homogenization temperatures and hydrocarbon occurrence in fluid inclusions from East Sichuan to northwestern periphery of the Xuefeng Uplift

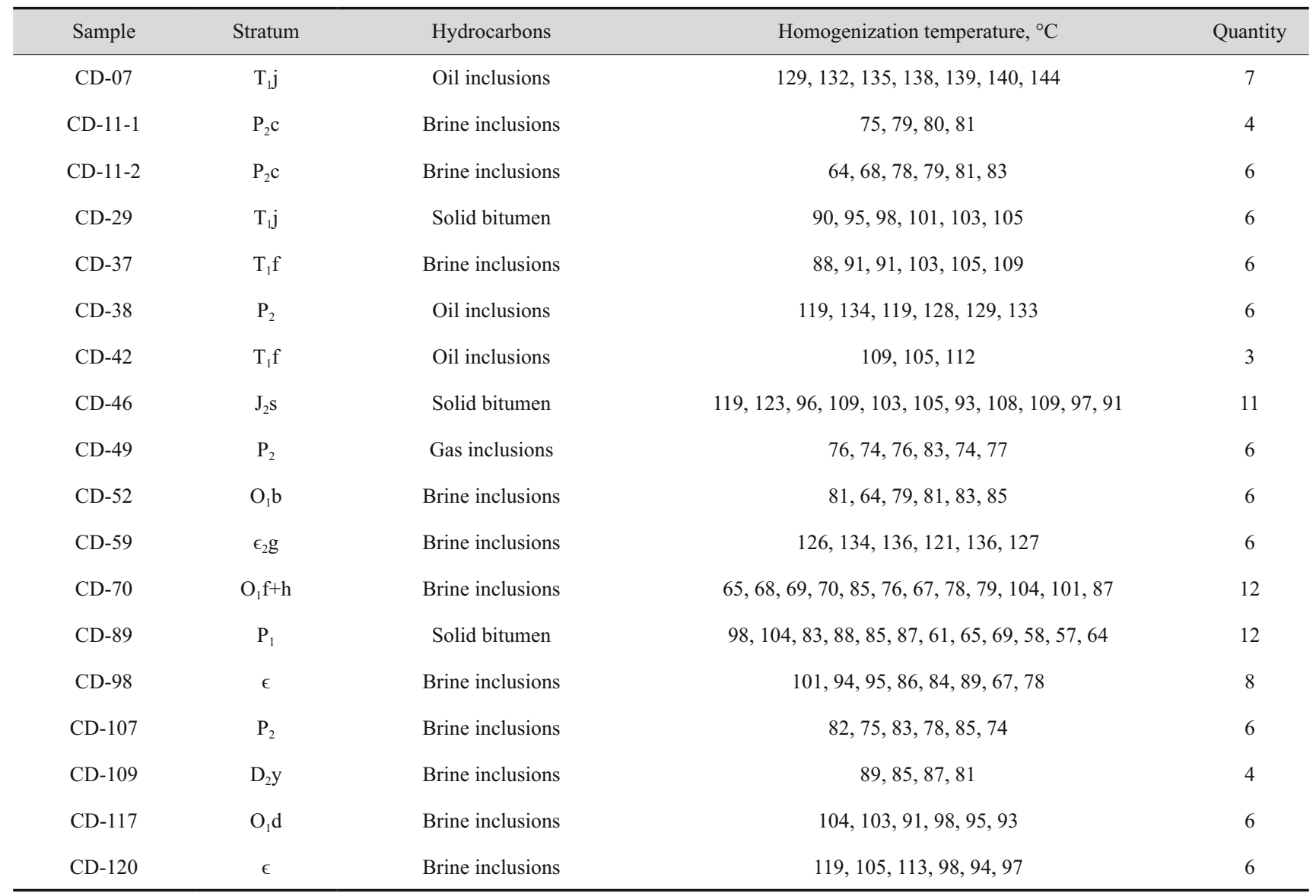




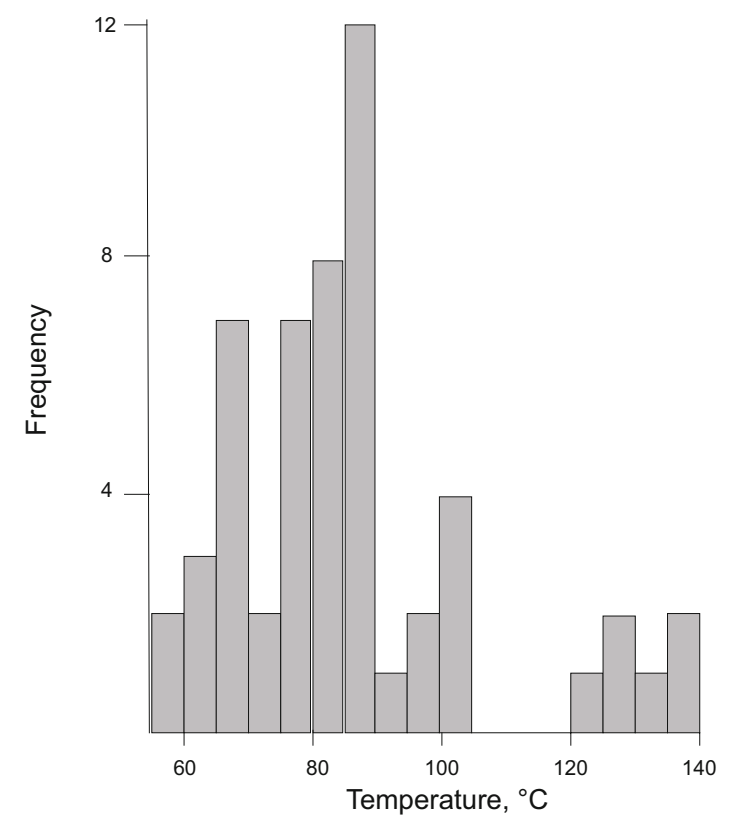

Fig. 4 The histogram of homogenization temperatures of fluid inclusions in West Hunan and Hubei

Two samples collected in the Ordovician and Cambrian were brine inclusions. The homogenization temperatures of all vein fluid inclusions were around $100^{\circ} \mathrm{C}$ and the fluid flow was weak. Low salinity, high metamorphic coefficient and desulfurization coefficient of the formation water in the northwestern periphery of the Xuefeng Uplift were poor for hydrocarbon preservation. However, in some wells, high salinity was found, showing good hydrocarbon preservation conditions, such as the well Zhuang $1(52.1 \mathrm{~g} / \mathrm{L})$ and Yang 2 $(20.5 \mathrm{~g} / \mathrm{L})$. High salinity and low metamorphic coefficient and desulfurization coefficient from Late Cretaceous to Paleogene in the rift basins showed that the formation water was diluted first and concentrated metamorphism occurred later. Multiple wells had oil and gas shows and low-yield commercial oil flows, so this area experienced transformation.

As near the Xuefeng Uplift, the thrusting made the oil and gas preservation conditions worse. The fluid activity and oil and gas preservation conditions of the Lower Paleozoic and Pre-Cambrian in the study area were worse than those in West Hunan and Hubei.

\section{Structural deformation and fluid flow from East Sichuan to the northwestern periphery of the Xuefeng Uplift}

Tectonic movements and fluid flow are complementary, and different periods and types of tectonic movement formed different structures and hence fluid flows (Shi and $\mathrm{Li}, 1991$ ). Faulting is an important structural style in the oilfield, and plays an important role in the hydrocarbon migration and reservoir formation.

The East Sichuan chevron anticline belt is located in the east of the Sichuan Basin, and there are many closed anticlines and gentle synclines (Fig. 2(a)). The fluids are well developed around the faults. The acoustic emission studies show that there were three tectonic movements, which provide channels for hydrocarbon migration. The main migration and accumulation period of gas is Late Jurassic Yanshan, and the gas in the Jiannan gas field is from the pyrolysis of Silurian and Permian source rocks. The acoustic emission experiments show the same results. Meanwhile, the Silurian source rocks reached their oil generation peak in the Early Jurassic, when the paleo-temperature was 76$122{ }^{\circ} \mathrm{C}$, which was similar to homogenization temperatures of fluid inclusions in East Sichuan. These results show that the tectonic movements and fluid flow are consistent (Shi and $\mathrm{Li}$, 1991). The main detachment of West Hunan and Hubei was Silurian and Lower Cambrian mudstone, which was deeper than that in East Sichuan. The low-angle thrust was well developed and a few faults broke through the surface, where the Lower Cambrian and Silurian were good for hydrocarbon preservation. The Nanshanping paleo-reservoir is the direct evidence for oil and gas migration. The Nanshanping paleo-reservoir exposed Pre-Cambrian and Cambrian, and other strata were denuded. The source rocks were black carbonaceous mudstone and coal stone of the Lower Cambrian Niutitang Formation. The Dengying dolomite forms a good reservoir in the Upper Sinian. The Lower Cambrian Niutitang, Qiongzhusi and Canglangpu formations provide good reservoir rocks. The paleo-reservoirs accumulated in the Early and Middle Triassic. The Middle Jurassic and Yanshan tectonic movement made the reservoirs break up, which was similar to the results of acoustic emission and fluid inclusions. Although there was no fault breaking through the surface, the reservoirs were exposed and fluid inclusions were well developed, which was caused by fault-related folding. The syncline was good for hydrocarbon preservation in West Hunan and Hubei, especially, the high structures, such as the Helaozi and Xianfeng traps in the Huaguoping syncline ( $\mathrm{Hu}$, 2002).

Because of the thrusting in the periphery of the Xuefeng Uplift, there are many high-angle thrusts in the front of the Xuefeng Uplift, but no reservoir and just a few brine inclusions. Besides these, the very considerable groundwater infiltration made the fault provide main channels for oil and gas loss.

\section{Conclusions}

Different characteristics of tectonic deformation and fluid flow from East Sichuan to the northwestern periphery of the Xuefeng Uplift suggested that the deformation gradually increased, hydrocarbon fluids gradually became less, and preservation conditions gradually became poor.

Breakthrough high-angle thrusts were well developed in East Sichuan. There were a large number of oil and gas inclusion bearing calcite veins in the sites where the thrust broke through the ground. It indicated that the Upper Paleozoic reached the limit of oil generation, and the overlying Mesozoic formations were a good cap. Compared with the other two regions, tectonic activity was weak and fluid flow was rich in East Sichuan, so the area which the Mesozoic covered was good for oil and gas preservation. There were many low-angle blind thrusts in West Hunan and 
Hubei, but only a few faults reached the surface. The Lower Cambrian and Silurian can be recognized as good caps for hydrocarbon preservation. The breakthrough high-angle thrusts were well developed in the northwestern periphery of the Xuefeng Uplift, with rare fluid flow and very considerable groundwater infiltration. Because of proximity to the Xuefeng Uplift, the reservoirs were almost destroyed.

\section{Acknowledgements}

This research is sponsored by the National Basic Research Program of China (Grant No. 2012CB214804, 2005CB422107 and G1999043305), the National Natural Science Foundation of China (Grant Nos. 41172125, 40972090, and 40672143), the National Key Scientific Project (Grant No. 2011ZX05002-006-007HZ, 2008ZX05005-002$008 \mathrm{HZ}-1)$, and the Doctoral Fund of Ministry of Education of China (Grant No. 200804250001). Research Institute of Petroleum Exploration and Development of SINOPEC, Southwest Oilfield Company of SINOPEC and Southern Branch Exploration Company of SINOPEC have given full support with fundamental geologic data.

\section{References}

Antonellini M and Aydin A. Effect of faulting on fluid flow in porous sandstones: geometry and spatial distribution. AAPG Bulletin. 1995. 79(5): 642-670

Cheng Y, Lu Z Y, Zhao L Z, et al. Study on the preservation condition of gas reservoirs in southwestern edge of Sichuan Basin. Petroleum Geology \& Experiment. 2005. 27(3): 218-221 (in Chinese)

Fan X L, Zhai C B and Deng M. Significance of Meso-Cenozoic tectonic movements in marine petroleum exploration in the south of China. Petroleum Geology \& Experiment. 2006. 28(6): 539-543 (in Chinese)

He Z L, Wang X W, Li S J, et al. The Yanshan movement and its influence on petroleum preservation in Middle-Upper Yangtze region. Petroleum Geology \& Experiment. 2011. 33(1): 1-11 (in Chinese)

Hu X F. Oil \& gas reservoir types in the western region of Hunan and Hubei and exploration orientation. Oil \& Gas Geology. 2002. 23(3): 300-303 (in Chinese)

Janssen C, Laube N, Bau M, et al. Fluid regime in faulting deformation of the Waratah Fault Zone, Australia, as inferred from major and minor element analyses and stable isotopic signatures. Tectonophysics. 1998. 294(1-2): 109-130

Jones G, Fisher Q J and Knipe R J. Faulting, Fault Sealing and Fluid Flow in Hydrocarbon Reservoirs. London: The Geological Society Special Publication. 1998. vii-xxi
Liu G X, Wo Y J, Pan W L, et al. Fluid characteristics and hydrocarbon preservation conditions in marine facies strata of the Middle-Upper Yangtze region. Petroleum Geology \& Experiment. 2011. 33(1): 1722 (in Chinese)

Lou Z H, Li M, Jin A M, et al. Hydrogeological and hydrogeochemical characteristics and hydrocarbon preservation conditions for marine strata in China. Acta Geologica Sinica. 2008. 81(3): 387-396 (in Chinese)

Mei L F, Dai S W, Shen C B, et al. Formation and disintegration of Mesozoic-Cenozoic intra-continental ramp zone in Middle and Lower Yangtze region. Geological Science and Technology Information. 2008. 24(4): 1-7 (in Chinese)

Mei L F, Liu Z Q, Tang J G, et al. Mesozoic intra-continental progressive deformation in western Hunan-Hubei-Eastern Sichuan provinces of China: evidence from apatite fission tracks and balanced crosssection. Journal of China University of Geosciences. 2010. 35(2): 161-174

Qiu Y Y. The division and the evaluation of hydrocarbon preservation in Yangtze marine stratigraphy. Marine Origin Petroleum Geology. 1996. 1(3): 39-44 (in Chinese)

Shen C B, Li X Q and Du X B. Some application of fluid inclusions to study of fault oilfield. Petroleum Geology \& Oilfield Development in Daqing. 2003. 22(4): 4-6 (in Chinese)

Shi J X and Li B C. Study of applications of organic inclusions as a discriminant indicator for gas migration. Oil \& Gas Geology. 1991. 12(2): 185-194 (in Chinese)

Sun Z M, He F Q and Li E Z. Advances of coupled dynamics study of faulting and fluid flow. Xinjiang Petroleum Geology. 2002. 23(4): 48-50 (in Chinese)

Tang L J and Cui M. Key tectonic changes, deformation styles and hydrocarbon preservation in Middle- Upper Yangtze region. Petroleum Geology \& Experiment. 2011. 33(1): 12-16 (in Chinese)

Tang L J, Jin W Z, He C B, et al. Key tectonic changes and staging differential structural deformation in superimposed basins. Xinjiang Petroleum Geology. 2009. 30(2): 163-167 (in Chinese)

Wang L S, Chen S S, Yang J J, et al. Geochemical characteristics of Carboniferous reservoir and fluid in the eastern Sichuan Basin. Natural Gas Exploration and Development. 2001. 24(3): 28-38, 21 (in Chinese)

Xu G S, Liu S G, Zhang Y J, et al. Hydrochemical condition of natural gas enrichment in east Sichuan Carboniferous system. Oil \& Gas Geology. 1999. 20(1): 15-19 (in Chinese)

Xu S H, Mei L F, Yuan C P, et al. Types, evolution and pool-controlling significance of pool fluid sources in superimposed basins: A case study from Paleozoic and Mesozoic in South China. Journal of China University of Geosciences. 2007. 18(1): 49-59

(Edited by Hao Jie) 